\title{
Mechanism of action of rabbit liver phosphoglucomutase
}

\author{
Haris JAMIL and John B. CLARKE* \\ Department of Biochemistry, Bedford College, Regent's Park, London NWI 4NS, U.K.
}

(Received 13 February 1985/9 May 1985; accepted 21 May 1985)

\begin{abstract}
Induced-transport tests with comparatively undegraded rabbit liver phosphoglucomutase show that the enzyme possesses a phosphoenzyme mechanism and that any interconversion of phosphoenzyme forms is very rapid. A relatively stable ${ }^{32} \mathbf{P}$ labelled phosphoenzyme was isolated, which exchanged label rapidly with substrates. The phospho group appears to be bonded to a serine residue on the enzyme.
\end{abstract}

Three possible mechanisms for phospho group transfer have been proposed for phosphoglucomutases (Fig. 1). All three mechanisms may be unequivocally distinguished by the use of isotopic induced-transport tests (Britton \& Clarke, 1968) and a phosphoenzyme mechanism identified by following the stereochemical course of phospho group transfer (Lowe \& Potter, 1981). Distinctions based upon inspection of initial-velocity patterns are equivocal when realistic mechanisms are examined, as is the case when the enzyme has a bisphosphatase activity (see the Theory section).

Phosphoglucomutase from rabbit liver has been reported to have a high bisphosphatase activity (Hashimoto \& Yoshikawa, 1966; Ueda et al., 1978). This may be the result of phosphoenzyme instability, as the phosphate content of the freshly isolated phosphoglucomutase is only $0.5-0.7 \mathrm{~mol} /$ mol of enzyme (Handler et al., 1965). The activity appears to be associated with type II phosphoglucomutase isoenzymes, which are only found with the liver mutase. These isoenzymes may possess an alternative mechanism for phospho group transfer, as they appear to behave as phosphoribomutases in addition to their function as phosphoglucomutases (Quick et al., 1972). To investigate these possibilities, the mechanism of action of rabbit liver phosphoglucomutase was investigated by the use of induced-transport tests. This is a very sensitive method of detecting minor kinetic pathways. Care was taken to ensure that little degradation of the enzyme occurred during

* To whom correspondence should be addressed, at: Department of Biochemistry, Royal Holloway and Bedford New College, Egham Hill, Egham, Surrey TW20 0EX, U.K.

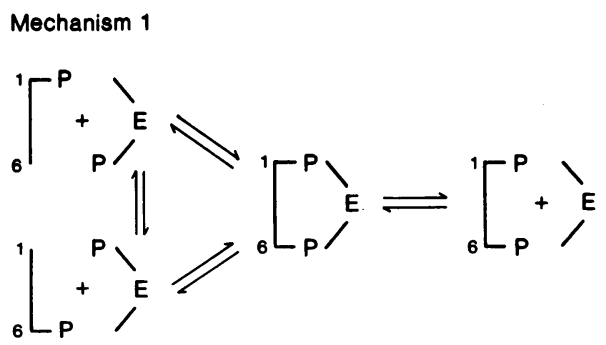

Mechanism 2<smiles></smiles>

Mechanism 3

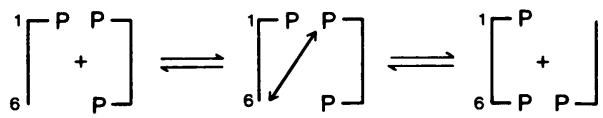

Fig. 1. Possible mechanisms for the phosphoglucomutase reaction

Mechanism 1 is the phosphoenzyme mechanism. Two alternative positions for phospho group (P) attachment are shown on the enzyme (E). It is also possible that an enzyme-cofactor complex could behave as a phosphoenzyme. This variant is called mechanism 1'. Mechanism 2 represents intramolecular transfer of a phospho group in which glucose 1,6-bisphosphate activates the enzyme indirectly. Mechanism 3 represents a sequential-addition mechanism in which there is an intramolecular transfer of phospho group from glucose 1,6-bisphosphate to the substrate. 
isolation, so that its kinetic properties were the same as those found in vivo.

\section{Theory}

\section{Kinetics of phosphoenzyme mechanisms}

When realistic phosphoenzyme mechanisms are considered, phosphoenzyme instability must be taken into account. Both phosphoglucomutases and phosphoglyceromutases possess bisphosphatase activities, and this feature is particularly marked with the latter (Pizer, 1960). For these enzymes the following initial velocity expression applies:

$$
\frac{1}{V_{\mathrm{i}}}=\frac{1}{V_{\max .}}\left(1+\frac{K_{\mathrm{m}}^{\mathrm{A}}}{[\mathrm{A}]}+\frac{K_{\mathrm{m}}^{\mathrm{B}}}{[\mathrm{B}]}+\frac{k_{\mathrm{PE}} \cdot K_{\mathrm{m}}^{\mathrm{A}} \cdot K_{\mathrm{m}}^{\mathrm{B}}}{k_{\mathrm{EB}} \cdot[\mathrm{AB}]}\right)
$$

Where $\mathrm{A}$ is the substrate and $\mathrm{B}$ the cofactor, $k_{\mathrm{PE}}$ is the rate constant for hydrolysis of the phosphoenzyme and $k_{\mathrm{EB}}$ is the rate of dissociation of the enzyme-cofactor complex. If a parallel-line pattern is to be obtained $k_{\mathrm{PE}}$ must be small and in addition $k_{\mathrm{EB}} \gg k_{\mathrm{PE}}$. However, exchange of ${ }^{32} \mathrm{P}$ label between substrates and cofactor appears to be slow for both phosphoglucomutases and phosphoglyceromutases (Ray \& Roscelli, 1964a; Grisolia \& Cascales, 1966; Cascales \& Grisolia, 1966), so that $k_{\mathrm{EB}}$ may be small and even comparable with $k_{\mathrm{PE}}$. Under these conditions an intersecting-line pattern will be obtained, and intersection on the abscissa will occur if $k_{\mathrm{EB}}=k_{\mathrm{PE}}$. Any convergence will be most pronounced at low substrate and cofactor concentrations, and will be unaffected by phosphoenzyme isomerization even if this is slow (Ray \& Roscelli, 1964b).

Evaluation of the degree of convergence requires a knowledge of the values of $k_{\mathrm{PE}}$ and $k_{\mathrm{EB}}$. The former can be estimated from measurements of phosphoenzyme stability, and the latter from the way in which radioactive label is distributed between product and cofactor when radioactively labelled substrate is added to a mixture of enzyme, substrate, product and cofactor at equilibrium. If a saturating concentration of cofactor is present, $k_{\mathrm{EB}}$ can be determined from eqn. (2) below:

Flux of substrate to product at equilibrium

Flux of substrate to cofactor

$$
=\frac{K_{\mathrm{i}}^{\mathrm{A}} \cdot V_{\max }^{\mathrm{F}}}{2 K_{\mathrm{m}}^{\mathrm{A}} \cdot[\mathrm{E}]_{\mathrm{T}}} \cdot \frac{1}{k_{\mathrm{EB}}}
$$

where $A$ is the substrate from which exchange is being measured, $K_{\mathrm{i}}^{\mathrm{A}}$ is the dissociation constant of the EA complex, $[\mathrm{E}]_{\mathrm{T}}$ is the total enzyme concentration, and $V_{\max }^{\mathrm{F}}$ is the maximum velocity of reaction in the forward direction.
Interpretation of initial-velocity patterns should be carried out with caution, as certain sequential addition mechanisms can give rise to parallel-line patterns. These mechanisms can be eliminated with the aid of isotopic data. Thus phosphoglucomutases generally exhibit a low rate of exchange of label between substrates and cofactor, and do not show co-transport with ${ }^{14} \mathrm{C}$-labelled substrates. These characteristics are incompatible with most sequential mechanisms.

\section{Materials and methods}

\section{Reagents and materials}

Glucose 1-phosphate, glucose 6-phosphate and glucose 1,6-bisphosphate were obtained from C. F. Boehringer und Soehne (Mannheim, Germany). DL-Glyceraldehyde 3-phosphate diethylacetal and rabbit muscle phosphoglucomutase were obtained from the same source.

Glucose 1-phosphate was purified as described by Ray \& Roscelli (1964a) to remove traces of glucose 1,6-bisphosphate.

Glucose 6-[32 P]phosphate was prepared from [32 $\mathrm{P}] \mathrm{P}_{\mathrm{i}}$ of high specific radioactivity (supplied by The Radiochemical Centre, Amersham, Bucks., U.K.) by modification of the method of Schendel \& Wells (1973) for the preparation of [ ${ }^{32}$ P]ATP. Pure glucose 6-[32 P]phosphate was obtained in approx. 50\% yield with a maximum specific radioactivity of $2.1 \mathrm{Ci} / \mathrm{mmol}$. This preparation contained less than $0.3 \%\left[{ }^{32} \mathrm{P}\right] \mathrm{P}_{\mathrm{i}}$.

Glucose 1,6-bis[32 P]phosphate of specific radioactivity $34 \mathrm{Ci} / \mathrm{mol}$ was prepared from glucose 6 [ $\left.{ }^{32} \mathrm{P}\right]$ phosphate by the method of Clarke et al. (1974).

$\left[{ }^{14} \mathrm{C}\right]$ Glucose 6-phosphate of specific radioactivity $142 \mathrm{Ci} / \mathrm{mol}$ (The Radiochemical Centre) contained $2.3 \%\left[{ }^{14} \mathrm{C}\right]$ glucose, which was removed by ion-exchange column chromatography (Schendel $\&$ Wells, 1973). Any $\left[{ }^{14} \mathrm{C}\right]$ glucose 1,6-bisphosphate contamination would also be removed by this treatment.

All radioactive material was stored salt-free in water at $-20^{\circ} \mathrm{C}$ before use.

\section{Induced-transport tests}

Induced-transport tests with ${ }^{32} \mathrm{P}$ - or ${ }^{14} \mathrm{C}$-labelled substrates were carried out as described by Britton \& Clarke (1968).

\section{Isolation of labelled phosphoenzyme}

Ten units of rabbit liver or muscle phosphoglucomutase were incubated for $5 \mathrm{~min}$ with $0.28 \mu \mathrm{Ci}$ of glucose 6- $\left[{ }^{32} \mathrm{P}\right]$ phosphate (specific radioactivity $609 \mathrm{Ci} / \mathrm{mol}), 0.28 \mu \mathrm{Ci}$ of $\left[{ }^{14} \mathrm{C}\right]$ glucose 6 -phosphate (specific radioactivity $142 \mathrm{Ci} / \mathrm{mol}$ ) and $0.04 \mathrm{nmol}$ of glucose 1,6-bisphosphate in $40 \mathrm{~mm}$-histidine/ 
$12 \mathrm{mM}$-Tris/HCl buffer, $\mathrm{pH} 7.6$, containing $2 \mathrm{mM}$ $\mathrm{MgCl}_{2}$ at $30^{\circ} \mathrm{C}$ in a final volume of $250 \mu \mathrm{l}$. Labelled phosphoglucomutase was then separated from substrates by passage down a Sephadex G-25 column as described by Clarke et al. (1974).

Alternatively 10 units of phosphoglucomutase were incubated for $30 \mathrm{~min}$ with $0.17 \mu \mathrm{Ci}$ of glucose 6-[32 $\mathrm{P}]$ phosphate (specific radioactivity $54.3 \mathrm{Ci} /$ $\mathrm{mol}$ ) and $0.12 \mathrm{nmol}$ of glucose 1,6-bisphosphate in $40 \mathrm{~mm}$-histidine $/ 12 \mathrm{~mm}$-Tris/ $\mathrm{HCl}$ buffer, $\mathrm{pH} 7.6$, containing $2 \mathrm{mM}-\mathrm{MgCl}_{2}$ at $30^{\circ} \mathrm{C}$ in a final volume of $200 \mu \mathrm{l}$. Incorporation of ${ }^{32} \mathrm{P}$ label into the phosphoenzyme was determined by using the rapid phenol extraction method (Rose, 1970).

\section{Results}

\section{Induced-transport tests}

The results from a number of induced-transport tests at low concentrations of glucose monophosphates are shown in Fig. 2. With ${ }^{32}$ P-labelled substrates, co-transport of ${ }^{32} \mathrm{P}$ from glucose 1 [32 P]phosphate into glucose 6-phosphate was ob- served. The glucose $1-\left[{ }^{32} \mathrm{P}\right]$ phosphate radioactivity fell to $37 \%$ of its original value and then returned to that value as chemical equilibrium was reached. Any decrease in ${ }^{32} \mathrm{P}$ radioactivity in the 1-position of glucose 1,6-bisphosphate would not affect cotransport significantly. The minimum glucose 1$\left[{ }^{32} \mathrm{P}\right]$ phosphate radioactivity is very similar to that expected for a phosphoenzyme mechanism (see line 3 in Fig. 2).

In similar experiments with ${ }^{14} \mathrm{C}$-labelled substrates, no induced transport was observed (line 1 in Fig. 2). Taken together, these results support mechanism 1 and exclude mechanisms 2 and 3 . However, mechanism 3 could give rise to the observed induced-transport pattern if the isomerization of the enzyme-glucose 1,6-bisphosphate complex is rate-limiting, as the degree of cotransport for ${ }^{14} \mathrm{C}$-labelled and ${ }^{32} \mathrm{P}$-labelled substrates will be diminished towards that of mechanism 1. This possibility has been excluded, for, in order to diminish the degree of co-transport of ${ }^{14} \mathrm{C}$ to less than that indicated by line 4 in Fig. 2, the $K_{\mathrm{m}}$ for glucose 1-phosphate would need to be at least

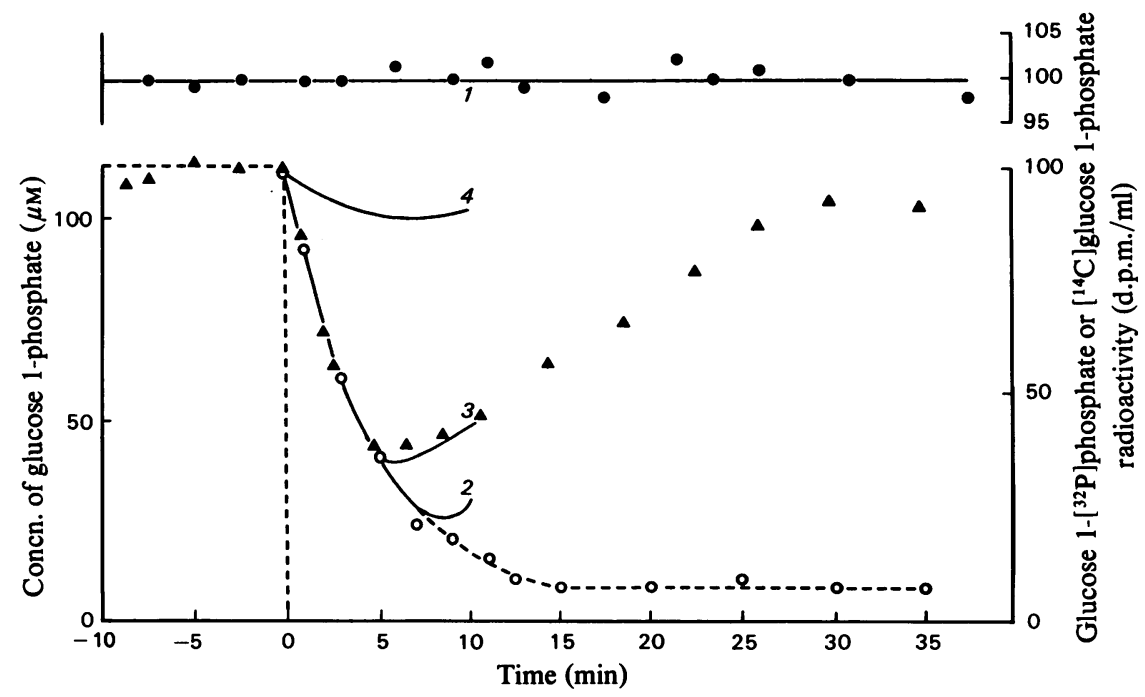

Fig. 2. Induced-transport tests with phosphoglucomutase at low substrate concentrations

Induced-transport tests were with ${ }^{32} \mathrm{P}$-labelled substrates showing co-transport and ${ }^{14} \mathrm{C}$-labelled substrates showing no induced transport. Labelled glucose 1-phosphate was incubated at $30^{\circ} \mathrm{C}$ with $2.2 \times 10^{-2}$ units of liver phosphoglucomutase in a histidine/Tris buffer, $\mathrm{pH} 7.4$, until equilibrium was reached. At zero time non-radioactive glucose 1-phosphate was added in small volume. Concentrations before additions: glucose 1-phosphate, $7 \mu \mathrm{M}$; glucose 6-phosphate, $40 \mu \mathrm{M}$; glucose 1,6-bisphosphate, $0.5 \mu \mathrm{M}$. Concentrations after addition: glucose 1-phosphate, $112 \mu \mathrm{M}$; glucose 6-phosphate, $39.8 \mu \mathrm{M}$; glucose $1,6-$ bisphosphate, $0.5 \mu \mathrm{M}$. $\bigcirc$, Concentration of glucose 1 -phosphate; $\Delta$, glucose $1-\left[{ }^{32} \mathrm{P}\right]$ phosphate radioactivity $\left(\right.$ d.p.m./ml) corrected for dilution at zero time;,$\left[{ }^{14} \mathrm{C}\right] \mathrm{glucose} 1-$ phosphate radioactivity (d.p.m./ml) corrected for dilution at zero time.The continuous lines are theoretical curves for glucose 1-phosphate radioactivity. For glucose 1-[32 P]phosphate and $\left[{ }^{14} \mathrm{C}\right]$ glucose 1-phosphate radioactivity the expected curves for mechanism 1 are 3 and 1 respectively, for mechanism 21 and 1 respectively, and for mechanism 32 and 3 respectively. Line 4 indicates the expected radioactivity changes for mechanism 3 with [ ${ }^{14} \mathrm{C}$ ]glucose 1 phosphate if isomerization of the enzyme-glucose 1,6-bisphosphate complex is slow with rate constant $288 \mathrm{~s}^{-1}$, or for mechanism 1 with glucose $1-\left[{ }^{32} \mathrm{P}\right]$ phosphate if isomerization of the phosphoenzyme is slow, with the same rate of isomerization. 
18-fold less than the experimental value of $31 \mu \mathrm{M}$ (J. B. Clarke \& H. Jamil, unpublished work).

Similarly, any isomerization of the phosphoenzyme (mechanism 1) should diminish the extent of co-transport of ${ }^{32} \mathrm{P}$ and lead to counter-transport ${ }^{14} \mathrm{C}$, especially at high substrate concentrations. No counter-transport of ${ }^{14} \mathrm{C}$ was observed, and at high substrate concentrations experiments indicated that the rate constants for any isomerization must be in excess of $2.7 \times 10 \mathrm{~s}^{-1}$. Thus these results are only compatible with mechanism 1 or $1^{\prime}$. The possibility that liver type II phosphoglucomutase isoenzymes catalyse phospho group transfer by an alternative mechanism is also excluded.

\section{Phosphoenzyme isolation}

The mutase was incubated with ${ }^{32} \mathrm{P}$-labelled and ${ }^{14} \mathrm{C}$-labelled substrates and then separated from the substrates by passage down a Sephadex G-25 column. Only ${ }^{32} \mathrm{P}$ radioactivity was associated with the enzyme. Thus the active form of the enzyme is a true phosphoenzyme, as suggested by mechanism 1 . Only $0.45-0.63 \mathrm{~mol}$ of phosphate is bound per mol of enzyme, in comparison with $0.84-1.19 \mathrm{~mol}$ of phosphate $/ \mathrm{mol}$ of enzyme found with mutase from rabbit.

Attempts to improve the incorporation of ${ }^{32} \mathrm{P}$ label into the phosphoenzyme by using the rapid phenol extraction method of Rose (1970) were not successful. When this method was used 0.52 $0.56 \mathrm{~mol}$ of phosphate $/ \mathrm{mol}$ of enzyme became labelled. When the labelled enzyme was incubated with a large excess of glucose 6-phosphate for a few seconds at room temperature more than $95 \%$ of the ${ }^{32} \mathrm{P}$ radioactivity was transferred to the substrates. Thus the phosphoenzyme is kinetically competent.

\section{Phosphoenzyme stability}

The stability of the ${ }^{32} \mathrm{P}$-labelled phosphoenzyme was determined at $30^{\circ} \mathrm{C}$ at $\mathrm{pH} 7.6$, as described by Clarke et al. (1974). The half-life of the phosphoenzyme was found to be $47.5 \mathrm{~h}$, and is very similar to that of the mutase from Micrococcus lysodeikticus, namely 50h (Clarke et al., 1974).

\section{Nature of the phosphoenzyme bond}

Incubation of 1 unit of ${ }^{32} \mathrm{P}$-labelled phosphoglucomutase for a short period with $0.48 \mathrm{M}-\mathrm{HClO}_{4}$ in the presence of $1 \mu \mathrm{mol}$ of $\mathrm{Na}_{2} \mathrm{HPO}_{4}$ and $1 \mathrm{mg}$ of bovine serum albumin indicated that $98 \%$ of the radioactivity was precipitated with the protein fraction. This suggests that the phospho group is attached to the enzyme by an acid-stable linkage.

Incubation of 5 units of ${ }^{32} \mathrm{P}$-labelled phosphoglucomutase in $0.25 \mathrm{M}-$ or $0.33 \mathrm{M}-\mathrm{NaOH}$ at $37^{\circ} \mathrm{C}$ indicated that ${ }^{32} \mathrm{P}$ radioactivity, exchangeable with substrates, had a half-life of $2.25 \mathrm{~h}$ or $1.31 \mathrm{~h}$ respectively. These values compare with half-lives for the phosphoenzyme from Micrococcus lysodeikticus of $2.4 \mathrm{~h}$ and $1.7 \mathrm{~h}$ respectively under the same conditions (Clarke et al., 1974) and of $1.5 \mathrm{~h}$ for the rabbit muscle phosphoenzyme in $0.5 \mathrm{M}-\mathrm{NaOH}$ (Kennedy \& Koshland, 1957). The similarity of these values suggests that the phospho group is attached to a serine residue in the liver enzyme.

\section{Discussion}

These results strongly support a simple phosphoenzyme mechanism for the enzyme (mechanism 1 in Fig. 1) in which the phospho group is bound to a serine residue and in which there is only one phosphoenzyme form. The mechanism is the same as that found with the phosphoglucomutases from rabbit muscle (Britton \& Clarke, 1968) and Micrococcus lysodeikticus (Clarke \& Britton, 1974) and is consistent with phospho group transfer via the exchange mechanism proposed by Ma \& Ray (1980).

In contrast with earlier reports (Hashimoto \& Yoshikawa, 1966; Ueda et al., 1978), the enzyme possessed only low bisphosphatase activity $\left(6.8 \times 10^{-6}\right.$ times the mutase activity). Consequently the initial-velocity pattern of the mutase should be characterized by parallel lines even at low concentrations of substrates and cofactor.

Though the bisphosphatase activity is greater than that found either with the flounder and shark muscle enzymes (Hashimoto \& Handler, 1966) or with rabbit muscle phosphoglucomutase (Ray et al., 1976), it is comparable with that of bovine liver phosphoglucomutase (Hirose et al., 1976). Thus the high glucose 1,6-bisphosphatase activity found in crude rabbit liver extracts must, as in bovine liver (Ueda et al., 1976), be due to the presence of other, possibly microsomal, phosphatases.

The relatively low degree of incorporation of ${ }^{32} \mathrm{P}$ label into the phosphoenzyme may indicate that the enzyme preparation contained contaminating proteins, though only a single band was seen on gel electrophoresis. Alternatively, the labelled enzyme-glucose 1,6-bisphosphate complex may dissociate to free enzyme and glucose 1,6-bisphosphate in addition to the formation of phosphoenzyme and glucose monophosphate. If the latter explanation is correct, then the enzyme-glucose 1,6bisphosphate $\rightleftharpoons$ phosphoenzyme-glucose monophosphate equilibrium must favour the enzymeglucose 1,6-bisphosphate complex, as dissociation of the cofactor is likely to be relatively slow (Ray \& Roscelli, 1964a).

\section{References}

Britton, H. G. \& Clarke, J. B. (1968) Biochem. J. 110, 161-179 
Cascales, M. \& Grisolia, S. (1966) Biochemistry 5, 3116 3122

Clarke, J. B. \& Britton, H. G. (1974) Biochem. J. 137, 453-461

Clarke, J. B., Birch, M. \& Britton, H. G. (1974) Biochem. J. 137, 463-467

Grisolia, S. \& Cascales, M. (1966) Biochem. Biophys. Res. Commun. 2, 200-205

Handler, P., Hashimoto, T., Joshi, J. G., Dougherty, H., Hanabusa, K. \& Rio, C. D. (1965) J. Med. Sci. 1, 11731179

Hashimoto, T. \& Handler, P. (1966) J. Biol. Chem. 241, 3940-3947

Hashimoto, T. \& Yoshikawa, H. (1966) J. Biochem. (Tokyo) 59, 427-429

Hirose, M., Ueda, M. \& Chiba, H. (1976) Agr. Biol. Chem. 40, 2433-2439

Kennedy, E. P. \& Koshland, D. E., Jr. (1957) J. Biol. Chem. 228, 419-431
Lowe, G. \& Potter, B. V. L. (1981) Biochem. J. 199, 693 698

Ma, C. \& Ray, W. J. (1980) Biochemistry 19, 751-759

Pizer, L. I. (1960) J. Biol. Chem. 235, 895-901

Quick, C. B., Fisher, R. A. \& Harris, H. (1972) Ann. Hum. Genet. 35, 445-453

Ray, W. J., Jr. \& Roscelli, G. A. (1964a) J. Biol. Chem. 239, 1228-1236

Ray, W. J., Jr. \& Roscelli, G. A. (1964b) J. Biol. Chem. 239, 3935-3941

Ray, W. J., Jr., Long, J. W. \& Owens, J. D. (1976) Biochemistry 15, 4006-4017

Rose, Z. B. (1970) Arch. Biochem. Biophys. 140, 508-513

Schendel, P. F. \& Wells, R. D. (1973) J. Biol. Chem. 248, 8319-8321

Ueda, M., Hirose, M. \& Chiba, H. (1976) Agr. Biol. Chem. 40, 2441-2448

Ueda, M., Hirose, M., Sasaki, R. \& Chiba, H. (1978) J. Biochem. (Tokyo) 83, 1721-1730 